九州大学学術情報リポジトリ

Kyushu University Institutional Repository

\title{
Detailed analyses of key phenomena in core disruptive accidents of sodium-cooled fast reactors by the COMPASS code
}

Morita, Koj i

Kyushu University

Zhang, Shuai

Kyushu University

Koshizuka, Seiichi

The University of Tokyo

Tobita, Yoshiharu

Japan Atomic Energy Agency

他

ht tp://hdl. hand le. net/2324/25656

出版情報 : Nuclear Engineering and Design. 241 (12)，pp.4672-4681，2011-12. Elsevier バージョン :

権利関係: (C) 2011 Elsevier B.V. 
Detailed analyses of key phenomena in core disruptive accidents of sodium-cooled fast reactors by the COMPASS code

Koji Morita*, Shuai Zhang

Kyushu University, 744 Motooka, Nishi-ku, Fukuoka 819-0395, Japan

Seiichi Koshizuka

The University of Tokyo, 7-3-1 Hongo, Bunkyo-ku, Tokyo 113-8656, Japan

Yoshiharu Tobita, Hidemasa Yamano

Japan Atomic Energy Agency, 4002 Narita, O-arai, Ibaraki 311-1393, Japan

Noriyuki Shirakawa, Fusao Inoue, Hiroaki Yugo, Masanori Naitoh, Hidetoshi Okada

The Institute of Applied Energy, 1-14-2 Nishi-Shinbashi, Minato-ku, Tokyo 105-0003, Japan

Yuichi Yamamoto, Masashi Himi, Etsujo Hirano, Sensuke Shimizu, Masaya Oue

Japan Systems Corporation, 1-1 Mimami-machi, Kawasaki-ku, Kawasaki 210-0015, Japan

* Corresponding author, Tel.: +81 802 3498; fax: +81 8023498

E-mail address: morita@nucl.kyushu-u.ac.jp (K. Morita)

\section{ABSTRACT}

A five-year research project has been initiated in 2005 to develop a code based on the MPS (Moving Particle Semi-implicit) method for detailed analysis of key phenomena in core disruptive accidents (CDAs) of sodium-cooled fast reactors (SFRs). The code is named COMPASS (Computer Code with Moving Particle Semi-implicit for Reactor Safety Analysis). The key phenomena include 1) fuel pin failure and disruption, 2) molten pool boiling, 3) melt freezing and blockage formation, 4) duct wall failure, 5) low-energy disruptive core motion, 6) debris-bed coolability, and 7) metal-fuel pin failure. Validation study of COMPASS is progressing for these key phenomena. In this paper, recent COMPASS results of detailed analyses for the several key phenomena are summarized. Simulations of GEYSER and THEFIS experiments were performed for dispersion 
and freezing behaviors of molten materials in narrow flow channels. In particular, the latter experiment using melt-solid mixture is also related to fundamental behavior of low energy disruptive core. CABRI-TPA2 experiment was simulated for boiling behavior of molten core pool. Expected mechanism of heat transfer between molten fuel and steel mixture was reproduced by the simulation. Analyses of structural dynamics using elastoplastic mechanics and fracture criteria were performed for SCARABEE BE+3 and CABRI E7 experiments. These two analyses are especially focused on thermal and mechanical failure of steel duct wall and fuel pin, respectively. The present results demonstrate COMPASS will be useful to understand and clarify the key phenomena of CDAs in SFRs in details.

Keywords: Reactor safety analysis, Core disruptive accident, Sodium-cooled fast reactor, Particle method, Code validation, Multi-phase flow

\section{Introduction}

Sodium-cooled fast reactors (SFRs) are developed for efficient utilization of nuclear resources and reduction of environmental burden. In hypothetical core disruptive accidents (CDAs) of SFRs, recriticality should be avoided, for example, by molten fuel relocation (Fauske et al., 2002). For CDA analysis, we need to solve complex multi-physics problems involving molten core behavior, boiling of the coolant, failure of the structure, etc. The fast reactor safety analysis code SIMMER-III has been developed and used to analyze CDAs in SFRs (Tobita et al., 2002). SIMMER-III is based on two-dimensional, multi-component, multi-phase, Eulerian description, and thermal-hydraulic interactions among components and phases are modeled using conventional engineering correlations. Therefore, to understand fundamental processes of CDAs in detail, specific analyses are necessary, in which the bulk correlations should be excluded as possible.

MPS (Moving Particle Semi-implicit) method was developed to analyze continuum (fluids and solids) by particles (Koshizuka and Oka, 1996). Governing equations are discretized to particle dynamics by substituting particle interaction models into differential operators. Since conventional grids are not used, complex motion with interfaces is clearly captured without grid tangling. The particles move as Lagrangian description, so that no numerical diffusion occurs on interfaces. The MPS method was applied to detailed two-phase flow analysis (Shirakawa, et al., 2001a, 2001b). Fuel-coolant interactions (FCIs) and molten core-concrete interactions were investigated in terms of severe accidents in light water reactors (Koshizuka et al., 1999a, 1999b, 2001; Ikeda et al., 2001). The MPS method was also used for SFR safety: sodium leakage and combustion (Iida, 1999; 
Koshizuka and Oka, 2000; Shibata et al., 2004), water jet injection into a sodium pool (Shirakawa, et al., 2001c), and water flashing in a sodium pool (Duan et al., 2006a, 2006b). It is expected, therefore, that the MPS method is also useful for the detailed analysis of complex phenomena in CDAs of SFRs.

A five-year research project was initiated in 2005 to develop a code based on the MPS method for detailed analysis of key phenomena in CDAs of SFRs. The code is named COMPASS (Computer Code with Moving Particle Semi-implicit for Reactor Safety Analysis). The key phenomena include 1) fuel pin failure and disruption, 2) molten pool boiling, 3) melt freezing and blockage formation, 4) duct wall failure, 5) low-energy disruptive core motion, 6) debris-bed coolability, and 7) metal-fuel pin failure. In this project, eutectic reactions between the metal fuel and the cladding material are also investigated by phase diagram calculation, classical and first-principles molecular dynamics. Fundamental studies concerning numerical methods are performed to support the code development of COMPASS. The past results of the present project can be found in the references (Koshizuka et al., 2006, 2007, 2008a, 2008b, 2009a, 2009b, 2009c; Yamano and Tobita, 2009, 2010a, 2010b; Zhang et al., 2009, 2010; Yamamoto et al., 2008, 2009; Shirakawa et al., 2009; Uehara et al., 2009; Ito, 2009; Ito et al., 2009; Himi et al., 2008, 2009).

The R\&D team of this research project is organized from the University of Tokyo, Kyushu University, Japan Atomic Energy Agency, Toyohashi University of Technology, the Institute of Applied Energy and Japan Systems Corporation. The R\&D activities are grouped to four subjects: COMPASS code development and validation, investigation of physical properties of metal fuel, theoretical studies and code design, and SIMMERIII analysis.

In this paper, recent results of the COMPASS validation study for key phenomena in CDAs of SFRs are summarized, which include melt freezing and blockage formation, low-energy disruptive core motion, molten pool boiling, duct wall failure, and fuel pin failure and disruption. The selected experiments are GEYSER (Berthoud and Duret, 1989), THEFIS (Maschek et al., 1990), CABRI TPA2 (Yamano et al., 2009), SCARABEE BE+3 (Kayser and Stansfield, 1994) and CABRI E7 (Charpenel et al., 2000), respectively.

\section{Outline of COMPASS}

\subsection{Overview}

COMPASS is designed to analyze multi-physics problems involving thermo-hydrodynamics and structural dynamics in a unified framework of the MPS method. The overall framework of the code is shown in Fig. 1. It consists of fluid dynamics, thermodynamics, and structural dynamics parts. The fluid dynamics part (Yamamoto 
et al., 2008, 2009) deals with multi-phase, multi-component fluids covering all the components modeled in SIMMER-III and eutectic components, which are included to model eutectic reactions between metal fuel and steel in metal-fueled reactors. Table 1 shows the material and phase components modeled in COMPASS. Enthalpy changes of components due to phase change processes of melting/freezing and vaporization/condensation are calculated in the thermodynamics part (Yamamoto et al., 2008, 2009) based on the non-equilibrium equilibrium heat- and mass-transfer models (Morita et al., 2003). The structural dynamics part (Koshizuka et al., 2008a; Shirakawa et al., 2009), which is not modeled in SIMMER-III, performs calculations of structure deformation and failure based on the elasto-plastic theory.

In COMPASS, thermodynamic and thermophysical properties of core materials, as shown in Table 1, are calculated using the same model and property data as those developed for SIMMER-III (Morita and Fischer, 1998; Morita et al., 1998). Lacking properties for the eutectic material of metal fuel and steel are supplied from the phase diagram provided by CALPHAD (Calculation of Phase Diagram) and by classical and first-principle molecular dynamics (Ito, 2009; Ito et al., 2009; Himi et al., 2008, 2009).

In general, numerical simulations based on moving particle methods require much computational resources to calculate large-scale phenomena. To solve this limitation, SIMMER-III, which can analyze the whole core in CDAs, will provide initial and boundary conditions as well as reference results for local calculation regions that can be addressed by COMPASS.

Integral code assessment of COMPASS is carried out by utilizing available experimental data, which have been obtained from a lot of in-pile and out-of-pile tests performed to investigate key phenomena in CDAs. Table 2 summarizes the selected experiments corresponding to the seven key phenomena in CDAs, and their characteristic behaviors and mechanisms to be analyzed by COMPASS.

\subsection{MPS method}

The governing equations for incompressible flows are the continuity equation and the Navier-Stokes equation:

$$
\frac{D}{D t}=0
$$

$$
\frac{D \boldsymbol{u}}{D t}=\nabla p+\nabla^{2} \boldsymbol{u}+\boldsymbol{g}
$$

where $D / D t$ is the Lagrangian derivative, $\boldsymbol{g}$ is the gravitational vector, $p$ is the pressure, $\boldsymbol{u}$ is the velocity vector, is the density, and is the viscosity. In the MPS method, the governing equations are 
discretized in terms of particles by substituting the following particle interaction models into differential operators (Koshizuka and Oka, 1996).

The discretized differential operators are described using the following weight function:

$w(r)=\left\{\begin{array}{rll}r_{e} / r & 1 & \left(0 \leq r<r_{e}\right) \\ 0 & \left(r_{e} \leq r\right)\end{array}\right.$

where $r$ is the distance between two particles and $r_{e}$ is the radius of interaction area. Particle number density of particle $i$ at the position $\boldsymbol{r}_{i}$ is defined as summation of the weight functions:

$n_{i}=\underset{j i}{w} w\left(\left|\boldsymbol{r}_{j} \quad \boldsymbol{r}_{i}\right|\right)$

The particle number density plays an important role in modeling the incompressibility. Although the weight function gives a sort of distance-dependent intensity of the interaction between particles, we better understand that it is the weight of particles to discretize differential operators.

Gradient operator of an arbitrary scalar quantity is modeled as the average of gradient vectors between particle $i$ and its neighboring particles within $r_{e}$ :

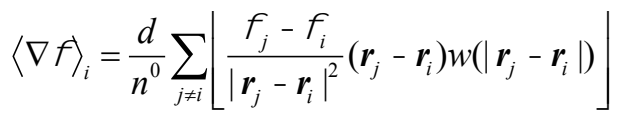

where $n^{0}$ is the particle number density in the initial particle arrangement. Laplacian operator is interpreted as a diffusion process of to the particles within $r_{e}$ :

$\left.\left\langle\nabla^{2}\right\rangle_{i}=\frac{2 d}{n^{0}} \sum_{j \neq i}\left[\begin{array}{ll}{ }_{j} & { }_{i}\end{array}\right) w\left(\left|\boldsymbol{r}_{j} \quad \boldsymbol{r}_{i}\right|\right)\right]$

where is the parameter to make the variance of equal to that of the analytical solution of a diffusion equation.

\subsection{Calculation algorithm}

The basic algorithm of the MPS method (Koshizuka and Oka, 1996) is based on a semi-implicit method similar to the SMAC method (Amsden and Harlow, 1970). In each time step, the governing equations are calculated through two steps. In the first step, temporal velocities $\boldsymbol{u}^{*}$ and positions $\boldsymbol{r}^{*}$ of particles are obtained using values at the current time step $k$ by explicitly solving the Navier-Stokes equation without the pressure gradient term: 
$\boldsymbol{u}^{*}=\boldsymbol{u}^{k}+\frac{\square t}{\square}\left(\triangle \nabla^{2} \boldsymbol{u}^{k}+\square \mathbf{g}\right)$

$\boldsymbol{r}^{*}=\boldsymbol{r}^{k}+\square t \times \boldsymbol{u}^{*}$

where $\square t$ is the time-step size. In the second step, the following pressure Poisson equation is solved with a source term representing the deviation of the particle number density:

$\nabla^{2} p^{k+1}=\square \frac{\square}{\square t^{2}} \frac{n^{*} \square n^{0}}{n^{0}}$

where $n^{*}$ is the temporal value of the particle number density. Correction of particle velocities is then calculated using the pressure gradient term:

$\boldsymbol{u}^{\prime}=\square \frac{\square t}{\square} \nabla p^{k+1}$

Finally, velocities and positions of particles are updated as next time step values:

$\boldsymbol{u}^{k+1}=\boldsymbol{u}^{*}+\boldsymbol{u}\lceil$

$\boldsymbol{r}^{k+1}=\boldsymbol{r}^{*}+\square t \times \boldsymbol{u}^{\prime}$

The above MPS algorithm for incompressible flows was extended to compressible-flow simulations with large density change (Koshizuka et al., 2009a) based on a unified algorithm for the finite difference method, CCUP (CIP-Combined Unified Procedure), which has been developed by Yabe and Wang (1991).

\section{Validation of COMPASS}

\subsection{Melt freezing and blockage formation}

The GEYSER out-of-pile experiments (Berthoud and Duret, 1989) were performed to clarify the fundamental phenomena of melt freezing and blockage formation in a narrow flow channel. In the experiments, the test section with a steel tube of an inner diameter of $4 \mathrm{~mm}$ and an outer diameter of $8 \mathrm{~mm}$ was immersed into a pool of liquid $\mathrm{UO}_{2}$ at $3,270 \mathrm{~K}$. The $\mathrm{UO}_{2}$ melt penetrated upwards into the tube by a pressure difference between the pool and the tube outlet. The initial temperature of the steel tube was $293 \mathrm{~K}$.

The COMPASS calculation was carried out in a three-dimensional geometry. In the calculation, the molten $\mathrm{UO}_{2}$ at $3,270 \mathrm{~K}$ initially filled the tube to the level of $0.2 \mathrm{~m}$ from the tube inlet. The melt was then injected into the tube at $293 \mathrm{~K}$ by a fixed pressure difference of $0.3 \mathrm{MPa}$ between the surface of the leading edge and the bottom of the melt. Particles newly generated at the inlet penetrated into the tube with the velocity determined by the pressure balance. In the case of the initial particle distance ( $\Delta$ of $0.125 \mathrm{~mm}$, the number of particles used 
in the calculation was about 100,000 at the initial state and 400,000 at $0.3 \mathrm{~s}$, at which blockage formation almost completed in the tube.

The simulation results of the penetration length and average velocity of the melt in the case of the GEYSER4 test are shown in Fig. 2. The development of the melt penetration agrees well with the experimental result. It can be seen that a higher spatial resolution $(\Delta=0.125 \mathrm{~mm})$ improves the result slightly. Fig. 3 indicates the profiles of $\mathrm{UO}_{2}$ volume fractions in the flow direction. Due to the heat transfer from the molten $\mathrm{UO}_{2}$ to the tube, the melt not only freezes into solid particles, but also forms solid crust on the tube surface. During the freezing processes, $\mathrm{UO}_{2}$ can be in a rheological state between its solidus and liquids points. The melt flow is blocked due to the development of solid particle formation in the tube. It is also suggested that the crust adhered on the tube surface increases thermal resistance between the melt and the tube due to relatively lower thermal conductivity of the crust. The present result shows that COMPASS can represent the typical melt freezing behaviors in CDAs.

\subsection{Low-energy disruptive core motion}

The THEFIS test (Maschek et al., 1990) was conducted to investigate the flowing and freezing process of melt-solid mixture in a colder flow channel. This process also relates to dynamic behavior of low energy disruptive core. In the experiments, molten $\mathrm{Al}_{2} \mathrm{O}_{3}$ superheated to $200 \mathrm{~K}$ was injected into the quartz tube of an inner diameter of $6 \mathrm{~mm}$ and an outer diameter of $8 \mathrm{~mm}$ by the pressure difference of 1 bar. The $\mathrm{Al}_{2} \mathrm{O}_{3} \mathrm{melt}$ penetrated and then froze in the tube under the effect of a solid-particle bed inside the tube.

The COMPASS calculations were performed by modeling the tube as a two dimensional geometry. The melt reservoir is represented by the quartz tube with a length of $0.1 \mathrm{~m}$. The initial temperatures of the melt and the quartz tube were $2,424 \mathrm{~K}$ and $300 \mathrm{~K}$, respectively. The reference pressure was fixed to be $0.1013 \mathrm{MPa}$. A constant pressure boundary condition was applied at the inlet to represent the driving pressure force. The initial particle distance was $0.25 \mathrm{~mm}$. Each solid particle in the bed was modeled by an $\mathrm{Al}_{2} \mathrm{O}_{3}$ cylinder with a diameter of $2 \mathrm{~mm}$, which was represented by 32 moving particles. The packing fraction of the solid bed is about 0.45 . To represent the interaction between solid particles, the distinct element method together with a coupling algorithm for solid-fluid mixture flows (Zhang et al., 2010) was applied to the present simulations.

Figs. 4 and 5 show the typical simulation results for the tests, Run\#6 and \#8, respectively. In these figures, transient distributions of melt and solid in the tube are presented at every $0.01 \mathrm{~s}$. In the test Run\#6, the mobile solid bed with a height of $80 \mathrm{~mm}$ was initially set at the inlet of the tube, while the bed with a height of $16 \mathrm{~mm}$

Fig. 5 
was fixed at a level of $31 \mathrm{~cm}$ from the inlet in the test Run\#8. According to the experimental observations, the solid bed lifted up as mixing the melt and particles in the test Run\#6, and the blockage due to the melt freezing was formed inside the particle bed in both of the tests, Run\#6 and \#8. As can be seen in Figs. 4 and 5, the blockage formation in the bed is successfully simulated by COMPASS. In the simulations, the melt penetration lengths in Run\#6 and \#8 are $0.05 \mathrm{~m}$ and $0.32 \mathrm{~m}$, respectively, which are in good agreement with the experimental results. In particular, the melt penetration behavior in the mobile bed observed in Run\#6 cannot be represented by the preset multi-phase flow modeling of SIMMER-III (Yamano and Tobita, 2010a). The present results demonstrate usefulness of COMPASS for simulations of melt-solid mixture flows with melt freezing.

\subsection{Molten pool boiling}

The CABRI-TPA2 test was simulated by SIMMER-III to investigate the mechanism of boiling heat transfer in a fuel-steel mixture pool (Yamano et al., 2009). In the test, stainless steel balls were embedded in a small capsule contained fresh granular $\mathrm{UO}_{2}$ with enrichment of $12.3 \%$. The fuel melting was induced by a simulated transient overpower (TOP). It was found that SIMMER-III calculations overestimate the capsule pressure caused by the steel vaporization after fuel melting. It was considered that in the test the pressure development was suppressed by a blanketing effect of vaporized steel on the surface of the steel balls. In fact, SIMMER-III calculation showed good agreement with measured pressure by assuming 1/200 of the heat transfer from the molten fuel to the steel droplet.

A three-dimensional calculation using COMPASS was performed for a single steel droplet of $1 \mathrm{~mm}$ in diameter immersed in a cylindrical vessel filled with molten fuel at 3,100 $\mathrm{K}$ as shown in Fig. 6. The initial droplet temperature, $3,081.5 \mathrm{~K}$, was set close to the steel boiling temperature so that steel droplet vaporization was initiated just after the calculation starts. An adiabatic condition was applied to the vessel wall. The initial particle distance was $0.025 \mathrm{~mm}$. The number of particles used in the calculation was more than 500,000.

Fig. 7 shows the side and cross sectional views of the steel droplet, where the steel vapor is indicated by red colored particles. Steel vapor, which is generated uniformly on the droplet surface just after the heat transfer is initiated from the molten fuel to the steel droplet, forms bubbles adhered on the droplet surface at around 0.5 ms, and then films the droplet again afterward. This transient behavior of the steel vapor might be caused by interactions due to the surface tension between fuel and steel. Fig. 8 indicates the interfacial area between the steel droplet and the molten fuel, which is normalized by the initial droplet surface area. It can be seen that the interfacial area decreases to $1 / 10 \sim 1 / 100$ of the initial one due to the development of the steel vapor, which 
blankets the steel droplet suppressing the heat transfer from the molten fuel to the steel droplet. The present result supports the SIMMER-III result that was obtained by reducing the heat transfer assuming the blanketing effect of the steel vapor.

\subsection{Duct wall failure}

Behavior of hexcan wall failure observed in the SCARABEE BE+3 in-pile test (Kayser and Stansfield, 1994) is simulated by COMPASS. In the test, a 37-pin bundle was surrounded by the first thin wall (hexcan TH1), an argon cooling and isolating channel, the second thick wall (hexcan TH2) simulating sodium flow in an inter-subassembly gap, a sodium cooling channel, the third thick wall (hexcan TH3), an insulation layer, and a protection tube (see Fig. 9). The test was initiated by a TIB (total instantaneous blockage) condition.

In the previous study (Shirakawa et al., 2009), overall analysis of the SCARABEE BE +3 test was performed using SIMMER-III. Failure behavior of the first wall TH1 was then analyzed by COMPASS considering structural mechanics (Uehara et al., 2009) for the wall TH1 under initial and boundary conditions extracted from SIMMER-III results. Fig. 9 illustrates a two-dimensional mesh cell configuration used in the SIMMER-III calculation. In the test, the failure of the wall TH1 was initiated just before $9.012 \mathrm{~ms}$ after TIB at 0 s. SIMMER-III reasonably simulated the TH1 failure, assuming the existence of a small amount of liquid steel adjacent to the wall $\mathrm{TH} 1$. The similar behavior was also reproduced by the two-dimensional COMPASS calculation even though there was a time delay in the TH1 failure. The COMPASS calculation also revealed that the TH1 failure could be caused only by structural deformation under a high temperature condition within the time similar to one predicted by SIMMER-III. This suggests that the TH1 failure should be caused by a complex of thermal and structural mechanism.

In this paper, we present results of a three-dimensional COMPASS analysis of the TH1 failure behavior. Fig. 10 shows the calculation setup for the COMASS code. In the present calculation, a half of one side of the hexcan TH1 and its surrounding four layers of fuel pin, sodium vapor, argon gap and TH2 wall were simulated for the axial length of $20 \mathrm{~cm}$. The initial particle distance was $0.5 \mathrm{~mm}$. The number of particles used in the calculation was about 435,000 . The detail of this test conditions is summarized in our previous paper (Uehara et al., 2009). The initial and boundary conditions were extracted from the SIMMER-III result at the onset of the TH1 failure. The COMPASS results of deformation and failure behavior of the wall TH1 are shown in Fig. 11, where the time zero is defined by the onset of the TH1 failure. Fig. 11 (a) indicates the particle arrangement for the five layers of fuel pin, sodium vapor, TH1, argon gap and TH2, while Fig. 11 (b) presents only TH1. As can 
be seen from Fig. 11, COMPASS reasonably simulates larger deformation of the wall TH1 around the midpoint of hexagonal duct side.

However, the wall TH1 fails at the hexagonal duct corner, which is not exposed by the largest deformation and is at relatively lower temperature. This failure behavior, which is indicated in Fig.11 (b) by white colored particles that are in plastic state, would be ascribed to larger stress concentration in the corner region due to smaller degrees of freedom. Nevertheless, it would be reasonable that the three-dimensional calculation leads to earlier failure of the wall TH1 than that by the two-dimensional one.

\subsection{Fuel pin failure and disruption}

CABRI-E7 is a single Ophélie.6 pin disruption test under TOP conditions in the CABRI nuclear reactor (Charpenel et al., 2000). The objectives of the E7 test analysis are to study fuel pin failure behavior, such as pellet cracking before TOP, and clad disruption under TOP due to pressure built up by fuel vapor and released fission product (FP) gas. The E7 test was newly analyzed with the reactor safety analysis code SAS4A (Tentner et al., 1985) to provide initial and boundary conditions for the COMPASS analysis. Fig. 12 shows the normalized power under TOP after pre-irradiation and CABRI rated power operation, and the cavity pressure calculated by SAS4A. Fig. 13 indicates the linear swelling in the radial direction of the fuel pin due to solid FP calculated by SAS4A.

Fig. 14 shows cracking behavior, simulated by the COMPASS calculation, in the fuel pellet after preirradiation under normal operation of the E7 test fuel. As indicated in Fig. 14 (a), the results obtained only considering thermal stress indicate that radial crackings occur from the center void to the outward region. Meanwhile, in Fig.14 (b), by modeling radial distribution of solid FP swelling as simulated by SAS4A, COMPASS reproduces occurrence of the crackings from the peripheral region of the pellet due to higher thermal neutron irradiation there.

Clad disruption behavior observed in the E7 test was simulated using COMPASS by coupling thermo-fluid and structural mechanics. In this calculation, fuel-pin conditions such as molten fuel pressure ( $\sim 40 \mathrm{MPa})$, fuel and clad temperatures (above 3,000 K and $\sim 1,000 \mathrm{~K}$, respectively) were based on the SAS4A result at $0.457 \mathrm{~s}$. This time is just before the cladding rupture in the SAS4A calculation, which occurs at $0.461 \mathrm{~s}$ as shown in Fig. 12. In the present COMPASS simulation, sodium in the coolant channel was not considered. As shown in Fig. 15 , where the time zero is defined by $0.457 \mathrm{~s}$ of the SAS4A result, the solid fuel in the peripheral region breaks and then the steel clad deforms, oscillating circumferentially in a very short time period. At the same time, a rip 
of the clad causes at the lower edge of the clad, and then extends upward instantaneously. This clad behavior would be consistent with our empirical knowledge about so-called rip rupture propagation. Although we can see the plastic deformation of the clad in Fig. 15, we should note that the plastic slope in the stress-strain relation is assumed almost the same as the elastic one in the present calculation. Under the present high temperature condition, constitutive models in the stress-strain relation are not sufficiently understood, although the clad failure behavior is sensitive to the plastic slope.

\section{Concluding remarks}

Integral code validation of COMPASS was performed for several key phenomena in CDAs. The analyzed experiments were GEYSER for melt freezing and blockage formation, THEFIS for low-energy disrupted core motion, CABRI TPA2 for molten pool boiling, SCARABEE BE+3 for duct wall failure, and CABRI E7 for fuel pin failure and disruption. The simulation results demonstrate that COMPASS has capability to reasonably represent characteristic behaviors and mechanisms involved in these key phenomena. It is expected that COMPASS will be utilized to understand and clarify complex multi-physics problems of multi-phase, multicomponent flow and structural dynamics in CDAs supporting simulation results by conventional safety analysis codes.

\section{Acknowledgments}

The present study was carried out within the task "R\&D of the Next Generation Safety Analysis Methods for Fast Reactors with New Computational Science and Technology" entrusted from the Ministry of Education, Culture, Sports, Science and Technology of Japan. The computation was mainly carried out using the computer facilities at Research Institute for Information Technology, Kyushu University.

\section{References}

Amsden, A.A. and Harlow, F.H., 1970. The SMAC method: A numerical technique for calculating incompressible fluid flows, LA-4370, Los Alamos National Laboratory.

Berthoud, G. and Duret, B., 1989. The freezing of molten fuel: Reflections and new results. In: Proc. 4th Topical Meeting on Nuclear Reactor Thermal-hydraulics (NURETH-4), Karlsruhe, Germany, 675-681.

Charpenel, J., et al., 2000. Fuel pin behavior under the slow power ramp transients in the CABRI-2 experiments. Nucl. Tech. 130, 252-271. 
Duan, R.-Q., et al., 2006a. Direct simulation of flashing liquid jets using the MPS method. Int. J. Heat Mass Transfer 49, 402-405.

Duan, R.-Q., et al., 2006b. Numerical analysis of flashing jet structure and droplet size characteristics. J. Nucl. Sci. Tech. 43, 285-294.

Fauske, H.K., et al., 2002. Assessment of the FBR core disruptive accident (CDA): The role and application of general behavior principles (GBPs). J. Nucl. Sci. Tech. 39, 615-627.

Fukano, Y., et al., 2009. CAFÉ experiments on the flow and freezing of metal fuel and cladding melts (1) - Test conditions and overview of the results. In: Proc. Int. Conf. on Fast Reactors and Closed Fuel Cycle Challenges and Opportunities FR09, Kyoto, Japan, IAEA-CN-176/03-11P.

Himi, M., et al., 2008. R\&D of the next generation safety analysis methods for fast reactors with new computational science and technology (6) Study of eutectic reaction between metals: FPMD approach. In: Proc. 16th Int. Conf. on Nuclear Engineering (ICONE16), Orlando, FL, USA, ICONE16-48482.

Himi, M., et al., 2009. Next generation safety analysis methods for SFRs (8) Analyses of eutectics between fuel and steel in metal fuel with FPMD code VASP. In: Proc. 17th Int. Conf. on Nuclear Engineering (ICONE17), Brussels, Belgium, ICONE17-75578.

Iida, M., 1999. Three dimensional particle method code for sodium leakage analysis in liquid metal reactor. In: Proc. 7th Int. Conf. on Nuclear Engineering (ICONE7), Tokyo, Japan, ICONE-7202.

Ikeda, H., et al., 2001. Numerical analysis of jet injection behavior for fuel-coolant interaction using particle method. J. Nucl. Sci. Tech. 38, 174-182.

Ito, T., 2009. Molecular dynamics study on melting phenomena in $\mathrm{Cu}-\mathrm{Ag}$ eutectic system. J. Power and Energy System 3, 261-271.

Ito, T., et al., 2009. Next generation safety analysis methods for SFRs (7) Potential model for classical molecular dynamics on Pu-Fe system. In: Proc. 17th Int. Conf. on Nuclear Engineering (ICONE17), Brussels, Belgium, ICONE17-75591.

Kayser, G. and Stansfield, R., 1994. SCARABEE experimental expertise on failure mechanisms of stainless steel walls attacked by molten oxide. In: Proc. Int. Topical Meeting on Advanced Reactors Safety (ARS '94), Pittsburgh, PA, USA.

Konishi, K., et al., 2007. The result of a wall failure in-pile experiment under the EAGLE project. Nucl. Eng. Des. 237, 2165-2174.

Koshizuka, S., Oka, Y., 1996. Moving-particle semi-implicit method for fragmentation of incompressible fluid. 
Nucl. Sci. Eng. 123, 421-434.

Koshizuka, S. Oka, Y., 2000. Moving particle semi-implicit method for analyzing large deformation of free surfaces. In: Proc. ASME Fluids Engineering Division Summer Meeting (FEDSM'00), Boston, MA, USA, FEDSM2000-11270.

Koshizuka, S., et al., 1999a. Numerical analysis of fragmentation mechanisms in vapor explosions. Nucl. Eng. Des. $189,423-433$.

Koshizuka, S., et al., 1999b. Numerical analysis of molten core-concrete interaction using MPS method. In: Proc. Workshop on Severe Accident Research in Japan (SARJ-99), Tokyo, Japan, JAERI-Conf 2000-015, 294-299.

Koshizuka, S., et al., 2001. Numerical analysis of crust formation in molten core-concrete interaction using MPS method. In: Proc. 9th Int. Conf. on Nuclear Engineering (ICONE9), Nice, France, ICONE-9307.

Koshizuka, S., et al., 2006. Multi-physics and multi-scale simulation for core disruptive accidents in fast breeder reactors. In: Proc. 5th Korea-Japan Symp. on Nuclear Thermal Hydraulics and Safety (NTHAS5), Jeju, Korea, 472-479.

Koshizuka, S., et al., 2007. Code development for core disruptive accidents in sodium-cooled fast reactors, IAEA Topical Meeting on Advanced Safety Assessment Methods for Nuclear Reactors, Daejeon, Korea.

Koshizuka, S., et al., 2008a. R\&D of the next generation safety analysis methods for fast reactors with new computational science and technology (1) Introduction of the project and development of structural mechanics module. In: Proc. 16th Int. Conf. on Nuclear Engineering (ICONE16), Orlando, FL, USA, ICONE16-48499.

Koshizuka, S., et al., 2008b. Code development for multi-physics and multi-scale analysis of core disruptive accidents in fast breeder reactors using particle methods. In: Proc. 16th Pacific Basin Nuclear Conf. (16PBNC), Aomori, Japan, P16P1086.

Koshizuka, S., 2009a. Next generation safety analysis methods for SFRs (1) brief introduction of the project and basic study for algorithm of particle method. In: Proc. 17th Int. Conf. on Nuclear Engineering (ICONE17), Brussels, Belgium, ICONE17-75556.

Koshizuka, S., et al., 2009b. COMPASS code development and validation: A multi-physics analysis of core disruptive accidents in sodium-cooled fast reactors using particle methods. In: Proc. 2009 International Congress on Advances in Nuclear Power Plants (ICAPP 2009), Tokyo, Japan, No.9329.

Koshizuka, S., et al., 2009c. Validation for multi-physics simulation of core disruptive accidents in sodium- 
cooled fast reactors by COMPASS code. In: Proc. 13th Int. Topical Meeting on Nuclear Reactor Thermal Hydraulics (NURETH-13), Kanazawa, Japan, N13P1133.

Maschek, W., et al., 1990. Experimental investigations of freezing phenomena of liquid/particle mixtures in the THEFIS facility and their theoretical interpretation. In: Proc. 1990 Int. Fast Reactor Safety Meeting, Snowbird, UT, USA, I, 519-529.

Mitchell, G.W. and Ottinger, C.A., 1984. The D10 Experiment: Coolability of $\mathrm{UO}_{2}$ debris in sodium with downward heat removal. NUREG/CR-4055, SAND84-1144.

Morita, K. and Fischer, E.A., 1998. Thermodynamic properties and equations of state for fast reactor safety analysis, Part I: analytic equation-of-state model. Nucl. Eng. Des. 183, 177-191.

Morita, K., et al., 1998. Thermodynamic properties and equations of state for fast reactor safety analysis, Part II: properties of fast reactor materials. Nucl. Eng. Des. 183, 193-211.

Morita, K., et al., 2003. SIMMER-III/IV heat- and mass-transfer model, - Model and method description -. JNC TN9400 2003-047, Japan Nuclear Cycle Development Institute.

Shibata, K., et al., 2004. Numerical analysis of jet breakup behavior using particle method. Nucl. Sci. Eng., 41, $715-722$.

Shirakawa, N., et al., 2001a. Development and verification study of the two-fluid particle interaction method Two-phase flow analysis free from experimental correlation-. Comp. Fluid Dynamics J. 9, 348-365.

Shirakawa, N., et al., 2001b. Analysis of the void distribution in a circular tube with the two-fluid particle interaction method. J. Nucl. Sci. Tech. 38, 392-402.

Shirakawa, et al., 2001c. Analysis of jet flows with the two-fluid particle interaction method. J. Nucl. Sci. Tech. $38,729-738$

Shirakawa, N., et al., 2009. Next generation safety analysis methods for SFRs (5) Structural mechanics models of COMPASS code and verification analyses. In: Proc. 17th Int. Conf. on Nuclear Engineering (ICONE17), Brussels, Belgium, ICONE17-75532.

Spencer, B.W., et al., 1985. Results of recent reactor materials tests on dispersal of oxide fuel from a disrupted core. In: Proc. Int. Mtg. on Fast Reactor Safety, Knoxville, TN, USA, 2, 877-882.

Tentner, A.M., et al., 1985. The SAS4A LMFBR whole core accident analysis code. In: Proc. Int. Mtg. on Fast Reactor Safety, Knoxville, TN, USA, 2, 989-998.

Tobita, Y., et al., 2002. The development of SIMMER-III, an advanced computer program for LMFR safety analysis. In: Proc. IAEA/NEA Tech. Mtg. on Use of Computational Fluid Dynamics (CFD) Codes for Safety 
Analysis Reactors Systems Including Containment, Pisa, Italy.

Uehara, Y., et al., 2009. Next generation safety analysis methods for SFRs (6) SCARABEE BE+3 analysis with COMPASS code featuring duct-wall failure. In: Proc. 17th Int. Conf. on Nuclear Engineering (ICONE17), Brussels, Belgium, ICONE17-75533.

Wright, A.E., et al., 2009. CAFÉ experiments on the flow and freezing of metal fuel and cladding melts (2) Results, analysis and applications. In: Proc. Int. Conf. on Fast Reactors and Closed Fuel Cycle - Challenges and Opportunities FR09, Kyoto, Japan, IAEA-CN-176/03-12P.

Yabe, T. and Wang, P.-Y., 1991. Unified numerical procedure for compressible and incompressible fluid. J. Physical Society of Japan 60, 2105-2108.

Yamamoto, Y., et al., 2008. R\&D of the next generation safety analysis methods for fast reactors with new computational science and technology (2) Development and verification of thermo-hydraulics module of the COMPASS code. In: Proc. 16th Int. Conf. on Nuclear Engineering (ICONE16), Orlando, FL, USA, ICONE16-48485.

Yamamoto, Y., et al., 2009. Next generation safety analysis methods for SFRs (3) Thermal hydraulics models of COMPASS code and experimental analyses. In: Proc. 17th Int. Conf. on Nuclear Engineering (ICONE17), Brussels, Belgium, ICONE17-75521.

Yamano, H. and Tobita, Y., 2009. Experimental analysis by SIMMER-III on molten fuel freezing and boiling pool behavior. J. Power and Energy System 3, 249-260.

Yamano, H. and Tobita, Y., 2010a. Experimental analyses by SIMMER-III on fuel-pin disruption and lowenergy disrupted core motion. J. Power and Energy System 4, 164-179.

Yamano, H. and Tobita, Y., 2010b. Experimental analyses by SIMMER-III on debris-bed coolability and metallic fuel freezing behavior. In: Proc. 18th Int. Conf. on Nuclear Engineering (ICONE18), Xi'an, China, ICONE18- 29296.

Yamano, H., et al., 2009. Transient heat transfer characteristics between molten fuel and steel with steel boiling in the CABRI-TPA2 test. Nucl. Tech. 165(2), 145-165.

Zhang, S., et al., 2009. Improvement of basic fluid dynamics models for the COMPASS code. J. Power and Energy System 3, 313-320.

Zhang, S., et al., 2010. Development of a computational framework on fluid-solid mixture flow simulations for the COMPASS code. J. Power and Energy System 4, 126-137. 
Table captions

Table 1 Material and phase components modeled in COMPASS.

Table 2 Validation of COMPASS for key phenomena in CDAs.

Figure captions

Fig. 1 Overall framework of the COMPASS code.

Fig. 2 Penetration length and average velocity of melt in the tube (GEYSER4 test).

Fig. 3 Volume fraction of crust, melt and particles in the tube (GEYSER4 test).

Fig. 4 Transient distribution of melt and solid in the tube (THEFIS Run\#6).

Fig. 5 Transient distribution of melt and solid in the tube (THEFIS Run\#8).

Fig. 6 Initial conditions of COMPASS analysis (CABRI-TPA2 test).

Fig. 7 Transient behavior of steel vapor around molten steel droplet (CABRI-TPA2 test).

Fig. 8 Interfacial area of fuel-steel contact normalized by the initial contact area (CABRI-TPA2 test).

Fig. 9 Mesh cell configuration for SIMMER-III analysis (SCARABEE BE+3 test).

Fig. 10 Calculation setup of COMPASS extracted from SIMMER-III results (SCARABEE BE+3 test).

Fig. 11 Deformation and failure behavior of the first thin wall TH1 (SCARABEE BE+3 test).

Fig. 12 Transient power and cavity pressure calculated by SAS4A (CABRI-E7 test).

Fig. 13 Linear swelling due to solid FP calculated by SAS4A (CABRI-E7 test).

Fig. 14 Cracking behavior in the fuel pellet (CABRI-E7 test).

Fig. 15 Disruption behavior of the fuel pin (CABRI-E7 test). 


\begin{tabular}{|c|c|c|c|c|c|c|c|}
\hline & \multicolumn{7}{|c|}{ Phase components } \\
\hline & \multirow{3}{*}{.ֶ, } & \multicolumn{5}{|c|}{ Solid } & \multirow{3}{*}{ 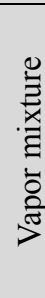 } \\
\hline & & \multirow{2}{*}{ 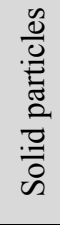 } & \multirow[t]{2}{*}{ 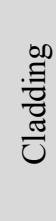 } & \multirow[t]{2}{*}{$\frac{\bar{\omega}}{\overline{0}}$} & \multirow[t]{2}{*}{$\begin{array}{l}\overrightarrow{\hat{n}} \\
\vec{U}\end{array}$} & \multirow{2}{*}{ 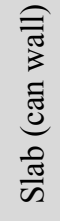 } & \\
\hline Material components & & & & & & & \\
\hline Fuel (MOX or metal) & Q & Q & & Q & प & & \multirow{5}{*}{ प } \\
\hline Structure (stainless steel) & Q & Q & Q & & & प & \\
\hline Coolant (sodium) & Q & & & & & & \\
\hline Eutectic & प & Q & & & प & & \\
\hline Fission gas $(\mathrm{Xe})$ & & & & & & & \\
\hline Control $\left(\mathrm{B}_{4} \mathrm{C}\right)$ & & Q & & 0 & & & \\
\hline
\end{tabular}

K. Morita et al., Table 1 


\begin{tabular}{|c|c|c|}
\hline Key phenomena & Characteristic behaviors and mechanisms & Selected experiments \\
\hline $\begin{array}{l}\text { Fuel pin failure and } \\
\text { disruption }\end{array}$ & $\begin{array}{c}\cdot \text { Pin failure } \\
\text { - Contact mode of molten materials to wall } \\
\end{array}$ & $\begin{array}{l}\text { CABRI E7 (Charpenel et al., } \\
\text { 2000) }\end{array}$ \\
\hline Molten pool boiling & $\begin{array}{l}\text { - Heat transfer between liquid fuel and steel } \\
\text { • Convection of fuel/steel mixture } \\
\text { - Heat transfer from fuel/steel mixture to wall }\end{array}$ & $\begin{array}{l}\text { CABRI TPA2 (Yamano et al., } \\
\text { 2009) }\end{array}$ \\
\hline $\begin{array}{l}\text { Melt freezing and } \\
\text { blockage formation }\end{array}$ & $\begin{array}{l}\qquad \text { Melt supercooling } \\
\text { - Thermal resistance of gaps between melt and wall } \\
\text { • Viscosity of melts around melting point }\end{array}$ & $\begin{array}{l}\text { GEYSER (Berthoud and Duret, } \\
\text { 1989) }\end{array}$ \\
\hline Duct wall failure & $\begin{array}{l}\cdot \text { Fuel crust formation } \\
\text { - Thermal/mechanical failure of wall }\end{array}$ & $\begin{array}{l}\text { SCARABEE BE+3 (Kayser and } \\
\text { Stansfield, 1994) } \\
\text { EAGLE WF (Konishi et al., } \\
\text { 2007) }\end{array}$ \\
\hline $\begin{array}{l}\text { Low-energy disrupted } \\
\text { core motion }\end{array}$ & $\begin{array}{l}\text { • Gas-liquid-solid three-phase flow } \\
\text { - Mobility of mixture of solid fuel and liquid steel }\end{array}$ & THEFIS (Maschek et al., 1990) \\
\hline Debris-bed coolability & $\begin{array}{c}\text { - Debris formation by FCIs } \\
\text { - Sodium flow and boiling inside debris bed } \\
\cdot \text { Self-leveling of debris bed }\end{array}$ & $\begin{array}{l}\text { CAMEL (Spencer et al., 1985) } \\
\text { SNL-ACRR D10 (Mitchell and } \\
\text { Ottinger, 1984) }\end{array}$ \\
\hline Metal-fuel pin failure & $\begin{array}{l}\text { - Eutectic formation at the interface between metal } \\
\text { fuel and steel wall }\end{array}$ & $\begin{array}{l}\text { CAFÊ (Fukano et al., 2009; } \\
\text { Wright et al., 2009) }\end{array}$ \\
\hline
\end{tabular}

K. Morita et al., Table 2 


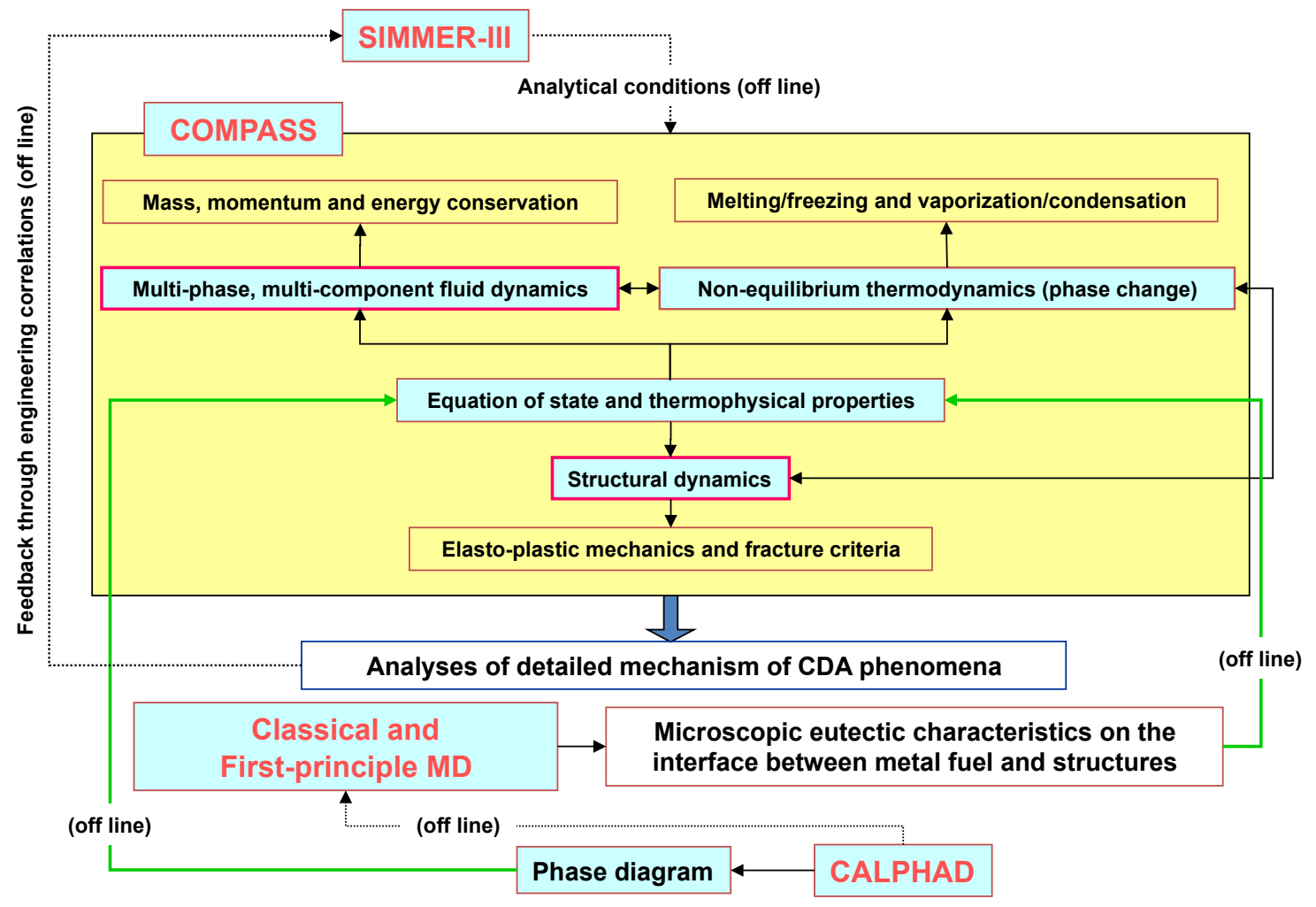

K. Morita et al., Fig. 1 


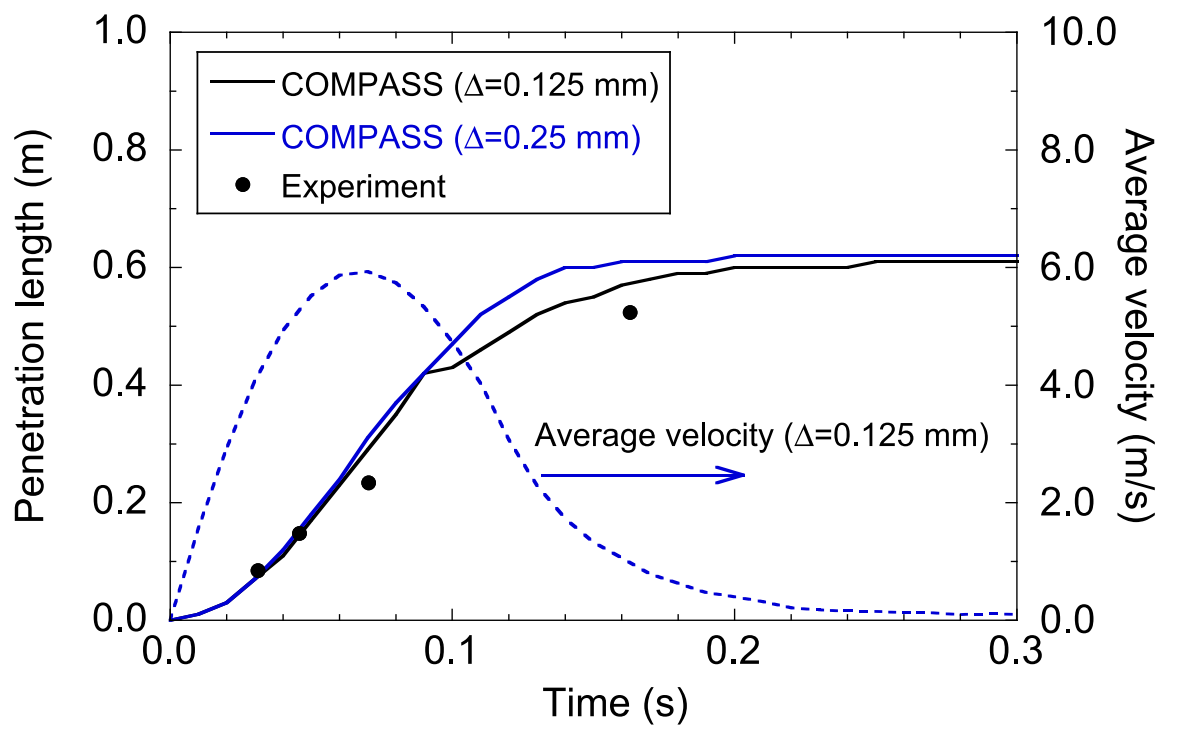

K. Morita et al., Fig. 2 


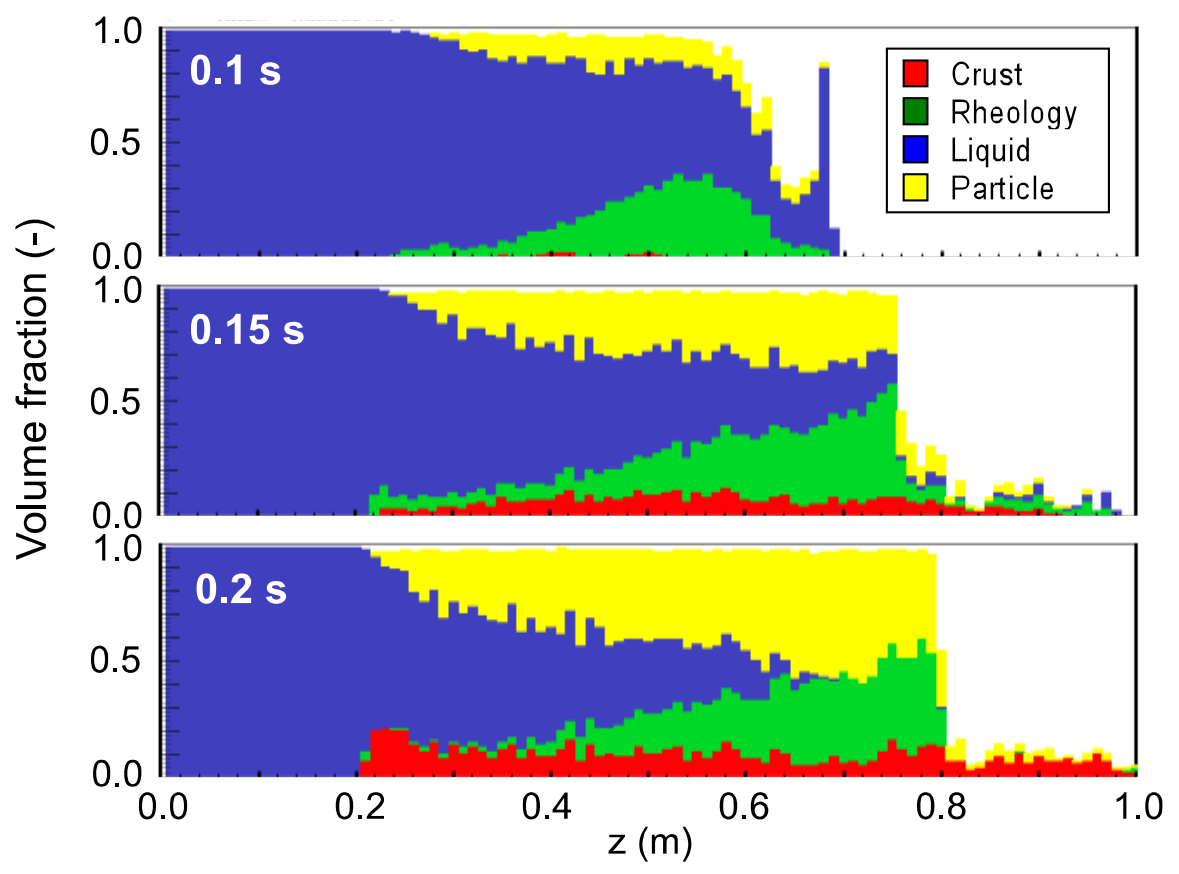

K. Morita et al., Fig. 3 


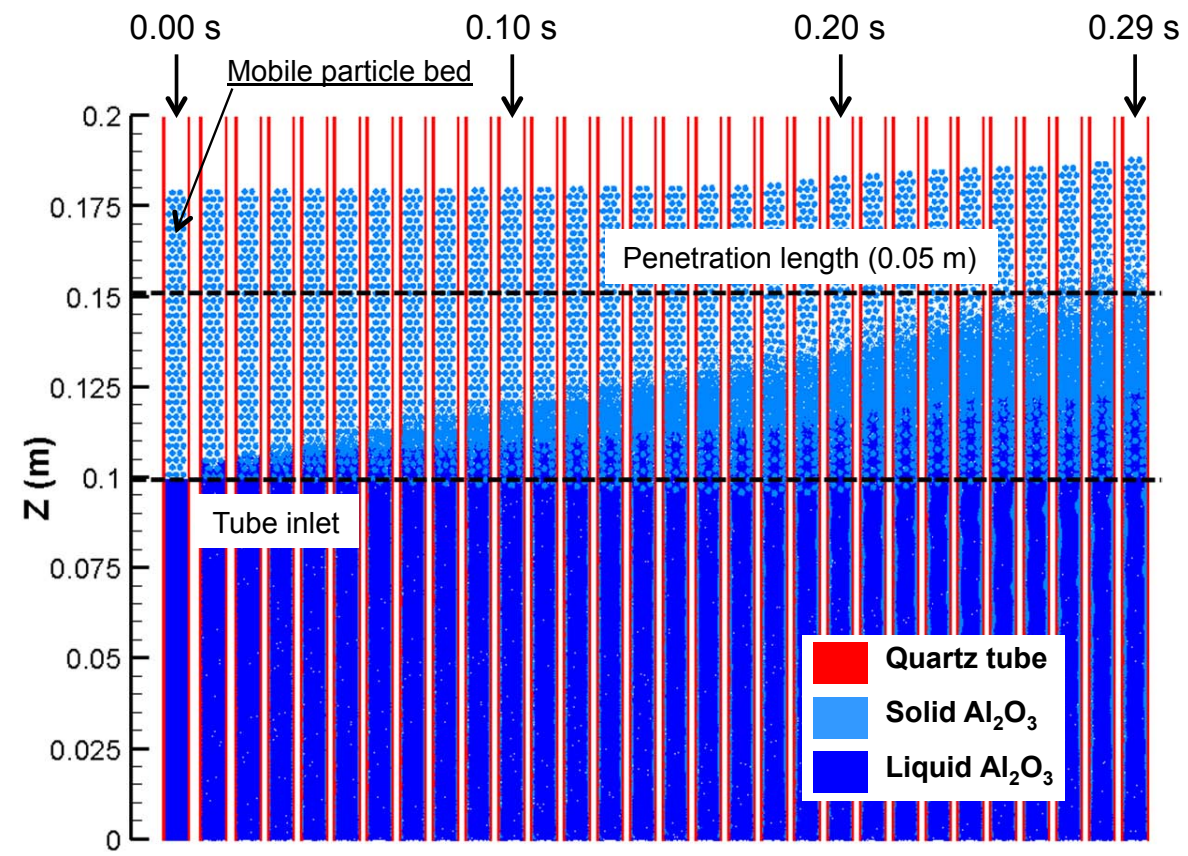

K. Morita et al., Fig. 4 


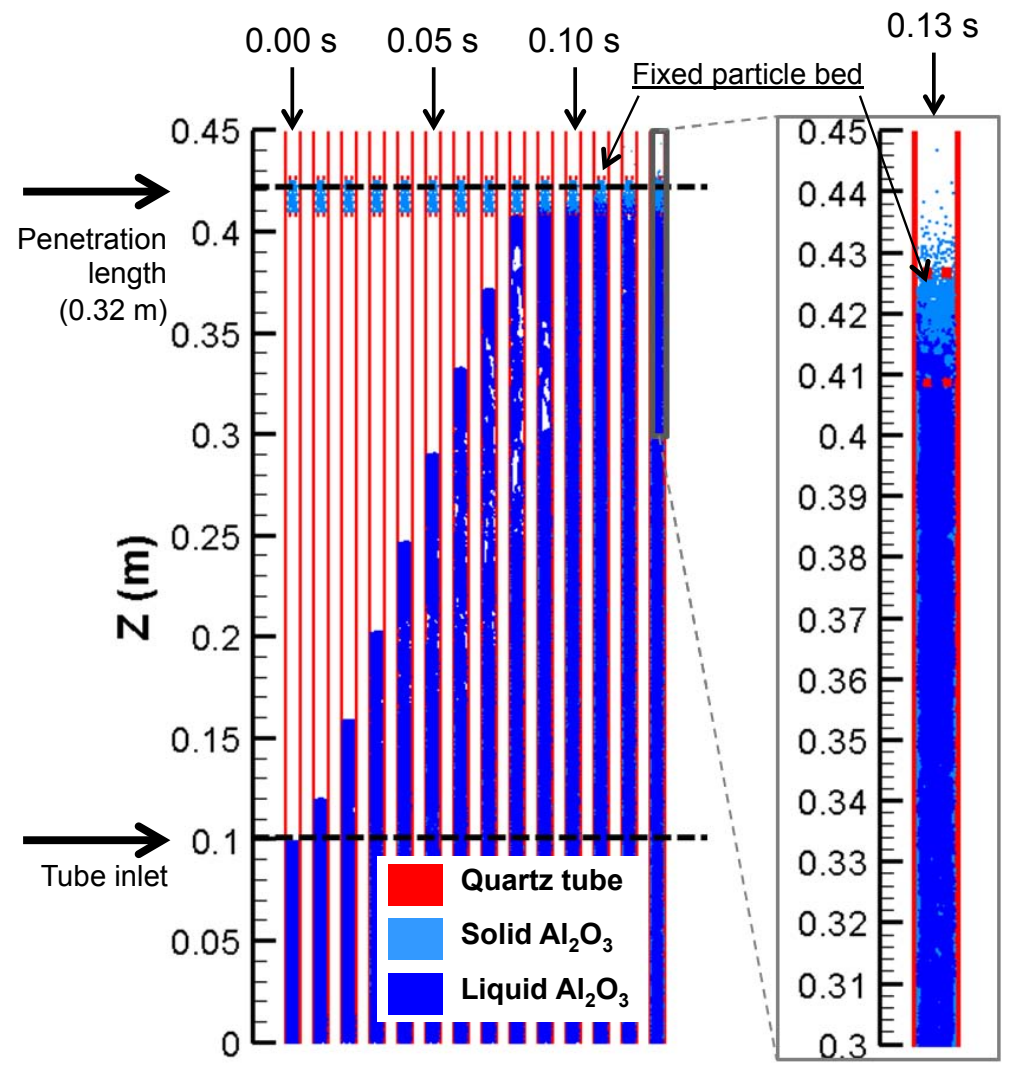

K. Morita et al., Fig. 5 


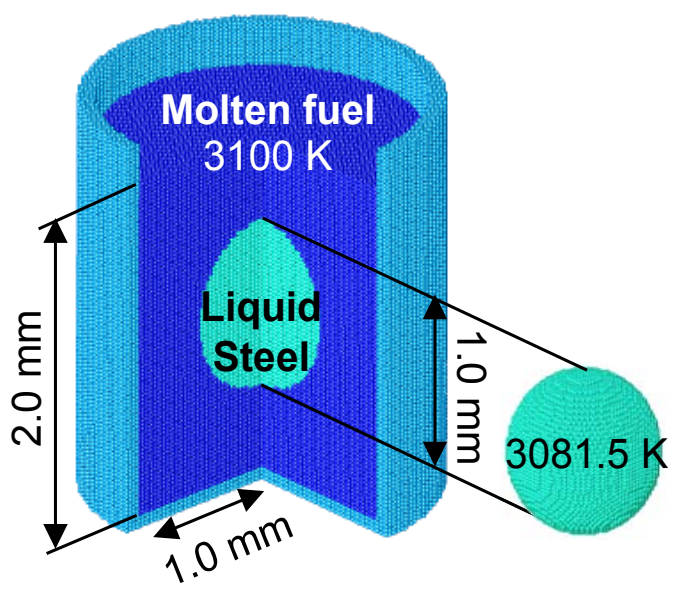

K. Morita et al., Fig. 6 


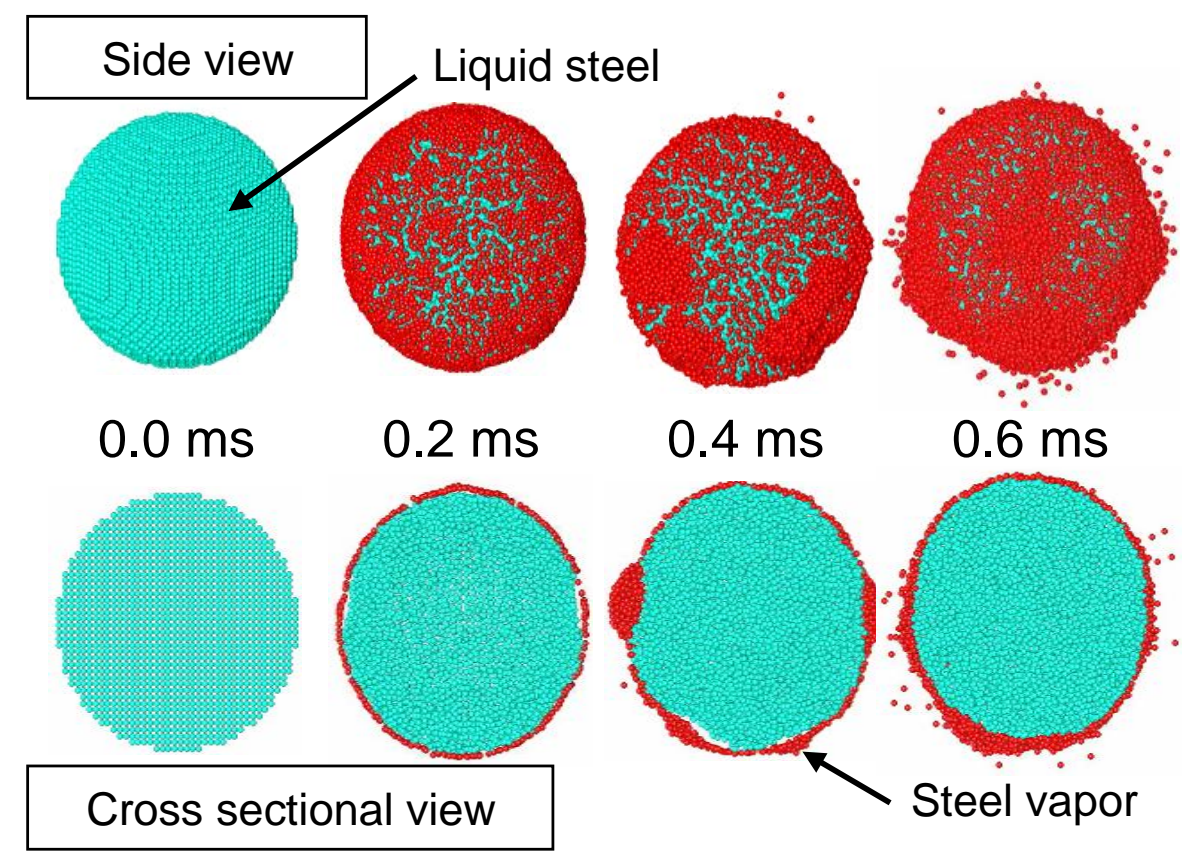

K. Morita et al., Fig. 7 


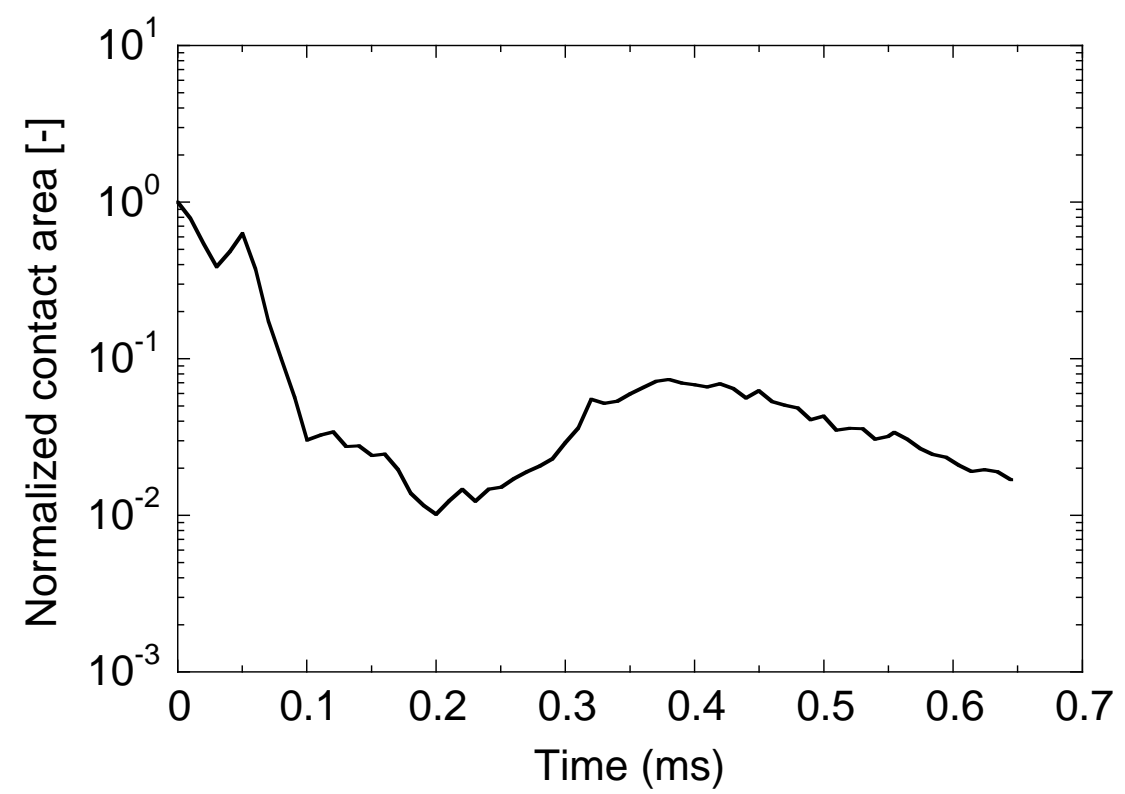

K. Morita et al., Fig. 8 


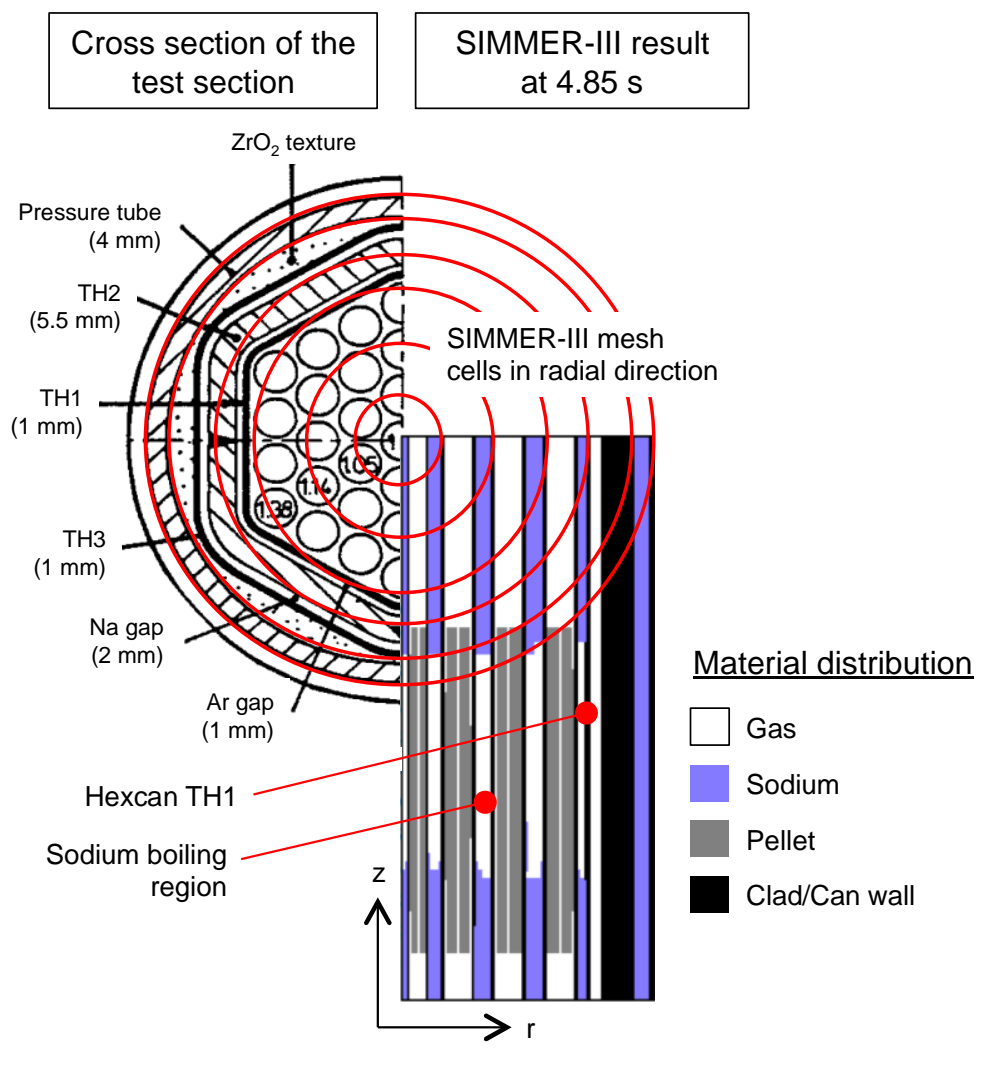

K. Morita et al., Fig. 9 


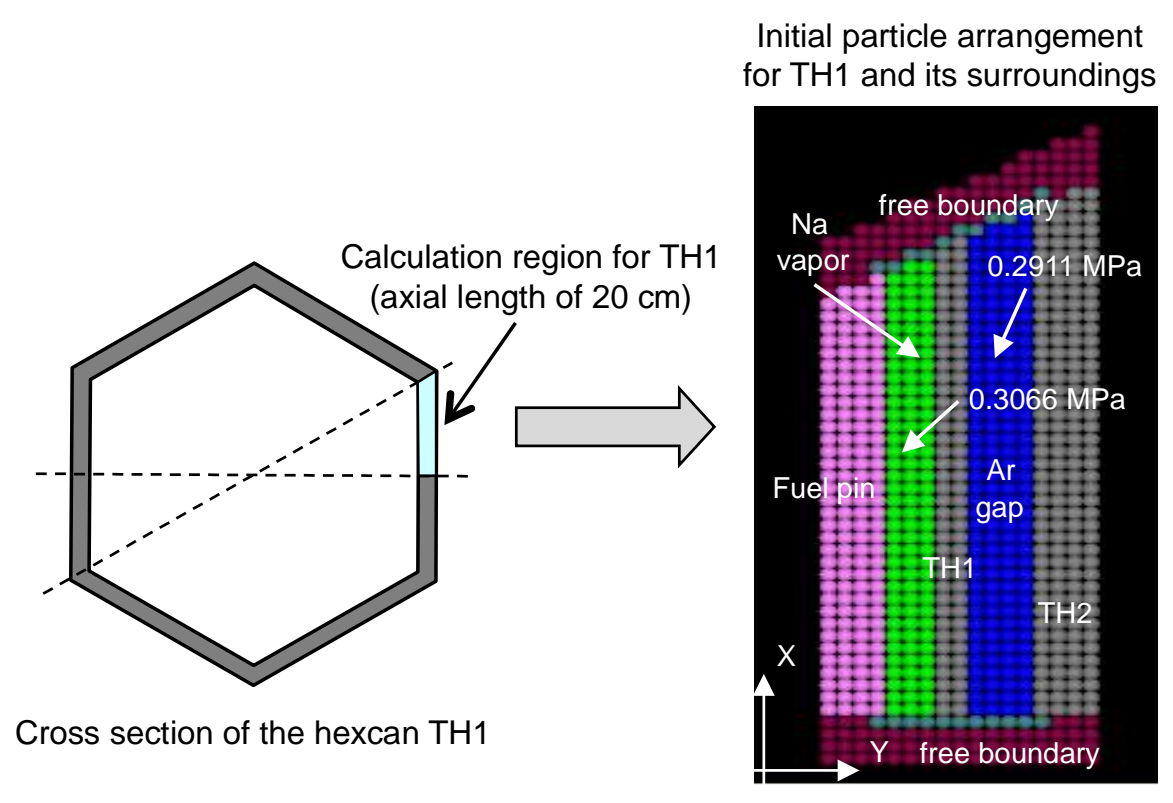

K. Morita et al., Fig. 10 


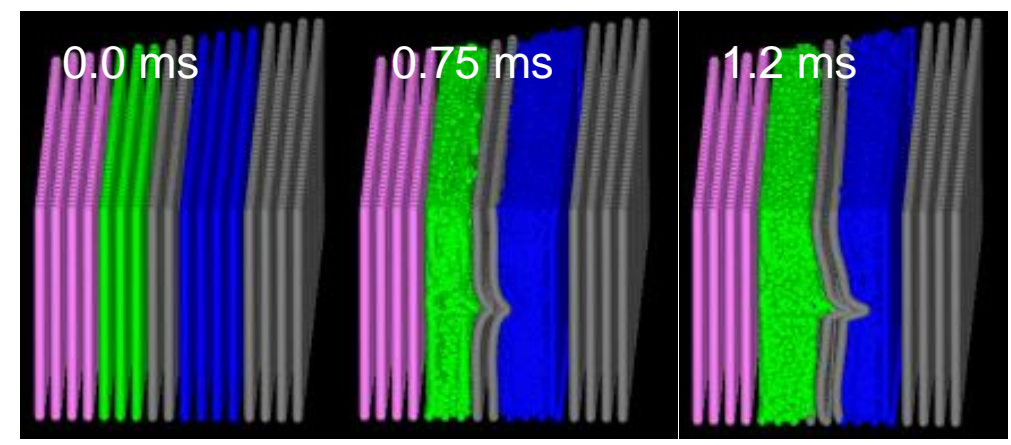

(a) Particle arrangement for five layers

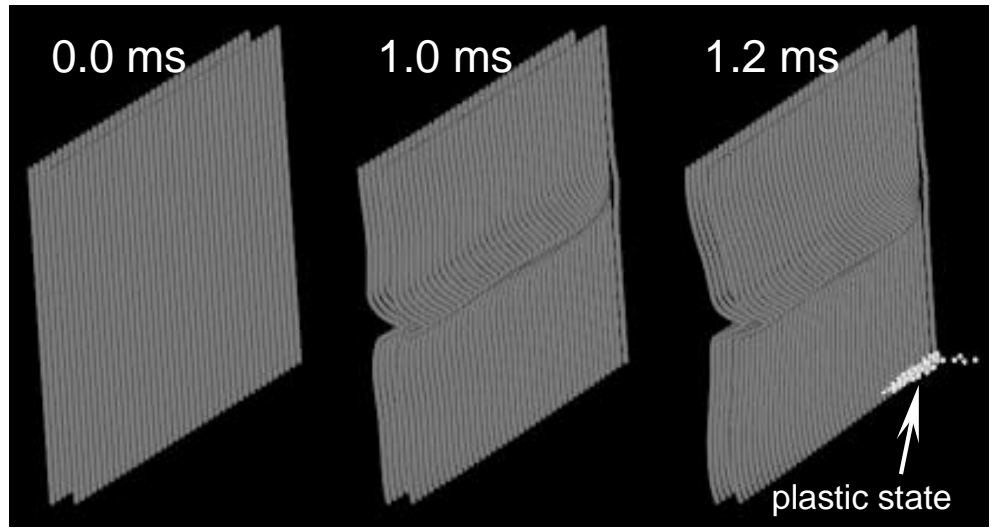

(b) Particle arrangement for TH1

K. Morita et al., Fig. 11 


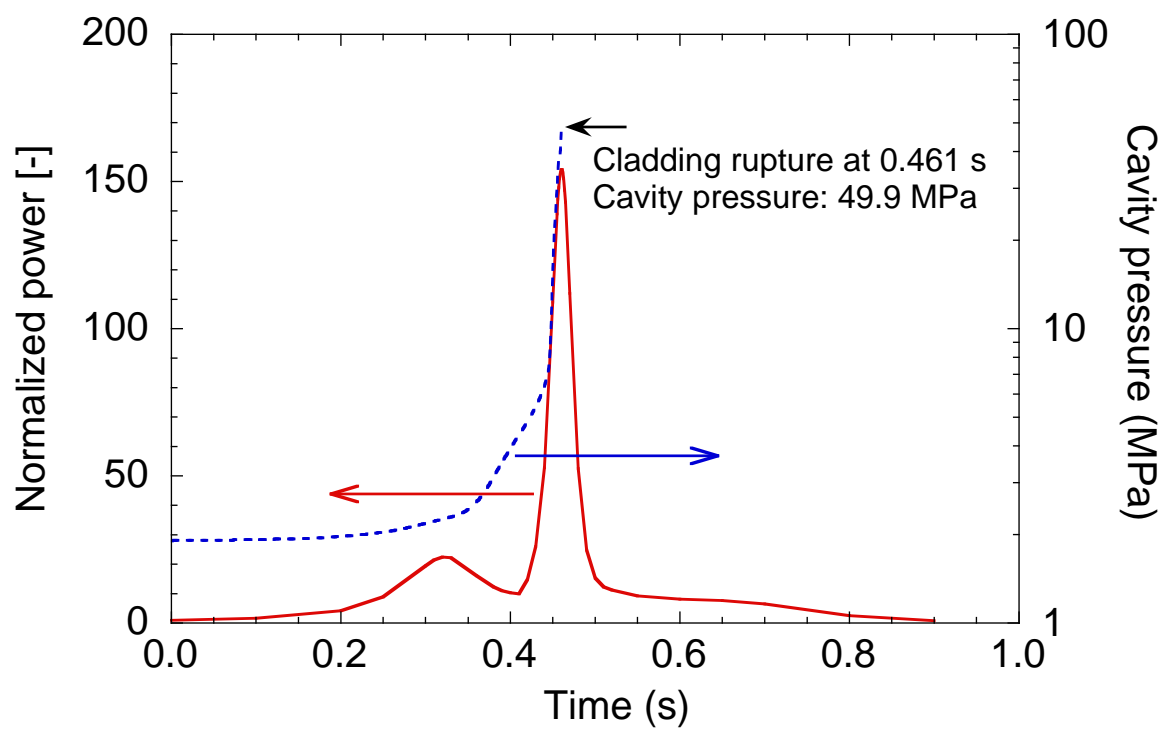

K. Morita et al., Fig. 12 


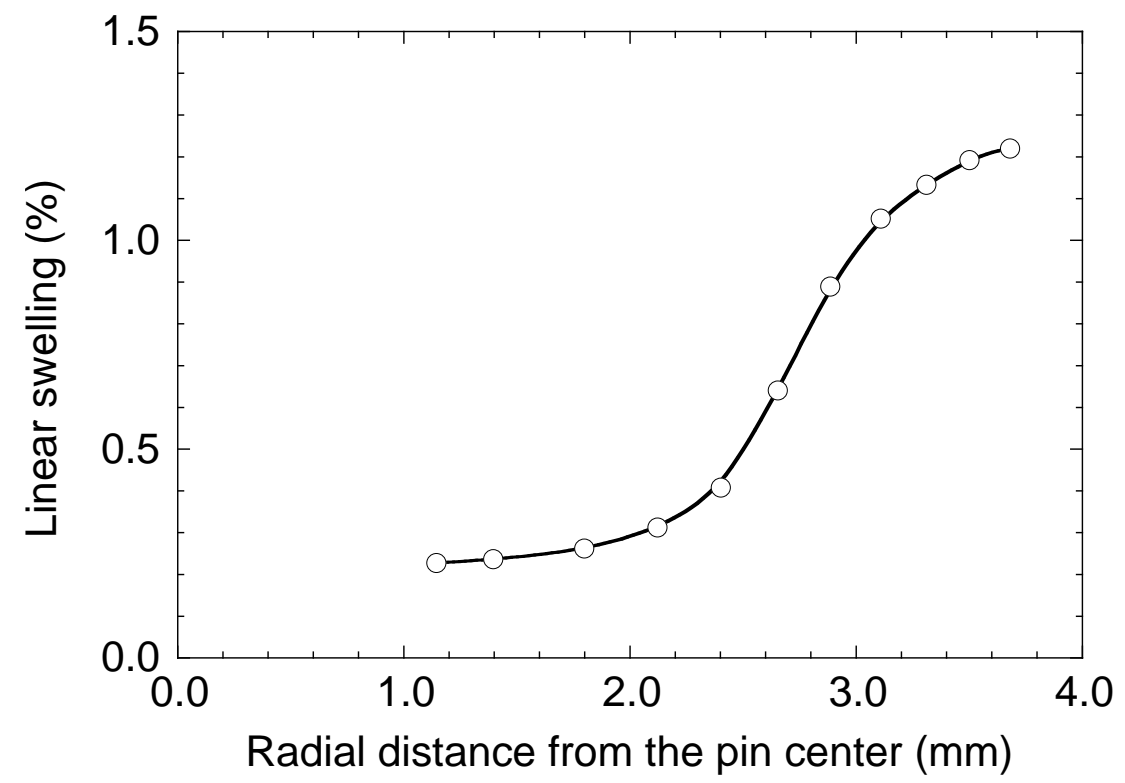

K. Morita et al., Fig. 13 


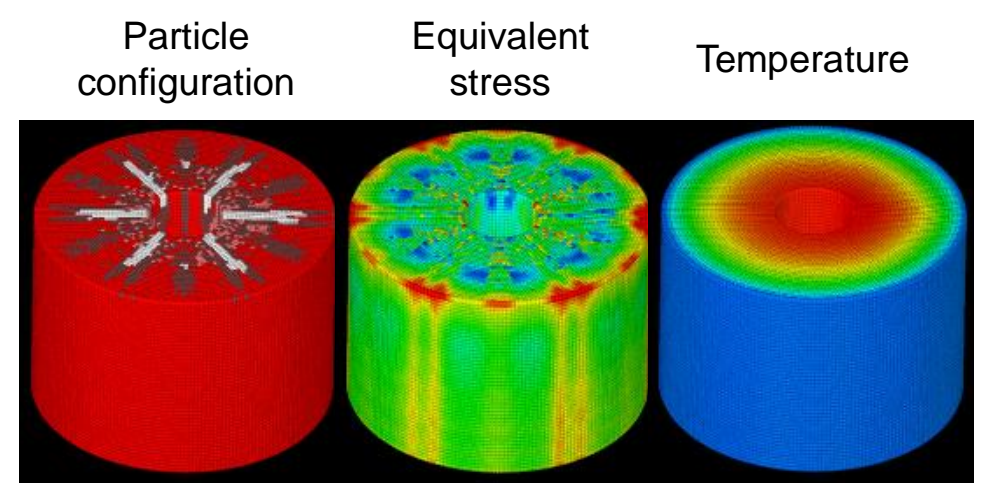

(a) Only with thermal stress

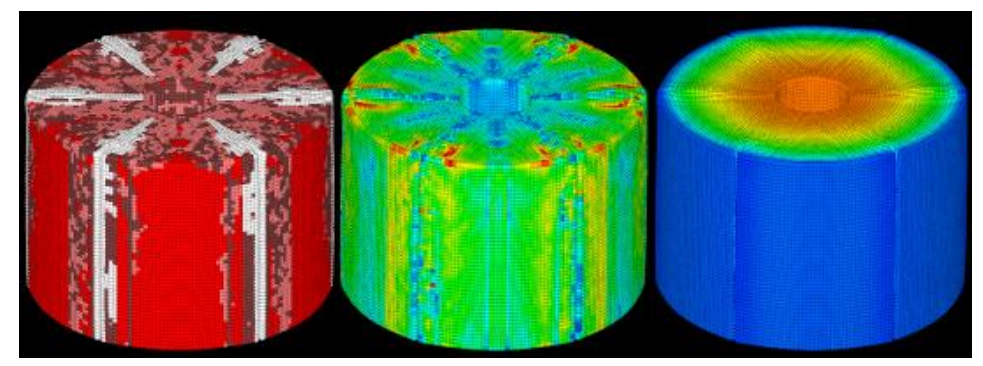

(b) With thermal stress and swelling

\begin{tabular}{|ll}
\hline Red & $:$ Elastic \\
Pink & $:$ Plastic \\
Brown & $:$ Plastic \\
& $\sim$ Elastic \\
Grey & $:$ Crashed
\end{tabular} \mid $\begin{array}{ll}\text { Blue } & : 0 \mathrm{MPa} \\
\text { Red } & : 400 \mathrm{MPa}\end{array} \quad$\begin{tabular}{lll} 
Blue & $: 1000 \mathrm{~K}$ \\
Red & $: 2300 \mathrm{~K}$ \\
\hline
\end{tabular}

K. Morita et al., Fig. 14 


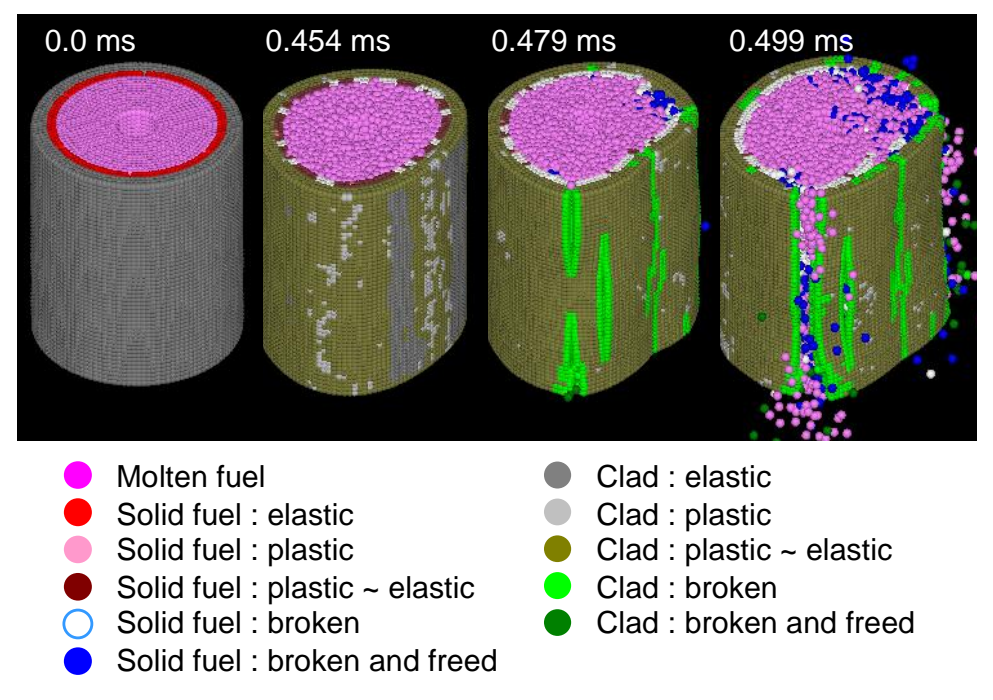

K. Morita et al., Fig. 15 